\title{
Inhibition effects of acetyl coumarines and thiazole derivatives on corrosion of zinc in acidic medium
}

\author{
A V SHANBHAG ${ }^{\dagger}$, T V VENKATESHA*, R A PRABHU ${ }^{\dagger \dagger}$ and B M PRAVEEN \\ Department of P.G. Studies and Research in Chemistry, Kuvempu University, Shankarghatta 577 451, India \\ ${ }^{\dagger}$ Department of Chemistry, S.D.M. College, Honavar 581 334, India \\ ${ }^{\dagger}$ Department of Chemistry, M.G.C. College, Siddapur 581 355, India
}

MS received 11 January 2008; revised 7 February 2011

\begin{abstract}
The corrosion inhibition characteristics of acetyl coumarine (AC), bromo acetyl coumarine (BAC) and thiazole derivatives (BTMQ and BTCQ) on the corrosion of zinc in $0 \cdot 1 \mathrm{M} \mathrm{HCl} \mathrm{solution} \mathrm{were} \mathrm{investigated} \mathrm{by} \mathrm{weight}$ loss, potentiodynamic polarization and impedance techniques. The inhibition efficiency increased with increase in inhibitor concentration upto $5 \times 10^{-4} \mathrm{M}$, then gave almost same inhibition efficiency. The polarization measurements indicated the mixed nature of inhibitors. The adsorption of compounds obeyed Langmuir's adsorption isotherm. The thermodynamic functions for adsorption processes were evaluated.
\end{abstract}

Keywords. Acetyl coumarines; adsorption isotherm; corrosion inhibition; impedance; zinc.

\section{Introduction}

White rust formation on zinc and galvanized products due to corrosion remains a serious commercial problem in spite of many available control methods. Also zinc gets corroded when exposed to different industrial environment and aqueous media. To inhibit the corrosion reaction of zinc in aqueous media, the inhibitors play a key role. The earlier research work revealed the use of a large number of organic compounds of different nature as corrosion inhibitors for zinc (Rodney and Leroy 1978; El-Mahdy and Mohmoud 1995; Gad Allah et al 1998). Most of these organic compounds are adsorbed on the metal surface and provide a barrier between metal and environment, thereby reducing the rate of corrosion. The effectiveness of inhibition depends on the nature and surface charge of the metal, the nature of the medium, the nature and chemical structure of the inhibitor molecule such as functional groups, aromaticity, the $\pi$ orbital character of the donating electron, steric factor, and electron density at the donor atoms (Stupnisek-Lisac and Metikos-Hukovia 1993; Tamil Selvi et al 2003).

Large numbers of inhibitors are available in literature but these types of inhibitors are generally toxic in nature (Aramaki 2002; Bellezze et al 2002; Arenas and Damborenea 2004; Ferreira et al 2004; SwiatowskaMrowiecka et al 2008). The use of chemical inhibitors has been limited because of the environmental threat, recently, due to environmental regulations. The toxic effects of most corrosion inhibitors have led to the use of inhibitors which are eco-friendly and harmless. The use of green corrosion

*Author for correspondence (drtvvenkatesha@yahoo.co.uk) inhibitors is well documented (Raja and Sethuraman 2008). However, most of these compounds are not only expensive, but also toxic to living beings. It is needless to point out the importance of cheap and safe inhibitors of corrosion (Bentiss et al 1999; Bouyanzer et al 2010).

In the present investigation an attempt has been made to evaluate the inhibiting action of acetyl coumarine (AC), bromo acetyl coumarine (BAC) and thiazole derivatives (BTMQ and BTCQ) on the corrosion of zinc in $0 \cdot 1 \mathrm{M} \mathrm{HCl}$ solution. Chemical and electrochemical methods were used to determine the rate of corrosion and corrosion inhibition efficiencies. The structures of organic additives used as inhibitors are shown in figure 1.

\section{Experimental}

\subsection{Preparation of inhibitors}

2.1a Acetyl coumarine: A mixture of substituted salicylaldehyde $(0.004 \mathrm{~mol})$ and ethylacetoacetate $(0.004 \mathrm{~mol})$ in $10 \mathrm{~cm}^{3}$ of ethyl alcohol was stirred at room temperature with few drops of piperidine for $8 \mathrm{~h}$. The resulting yellow coloured solid obtained was filtered, washed with excess of chilled alcohol, dried and crystallized (Knoevengel 1898; Buu-Hoi et al 1957).

2.1b Bromo-acetyl coumarine: 3-acetyl coumarine $(0.004 \mathrm{~mol})$ in $10 \mathrm{~cm}^{3}$ of chloroform (alcohol free) was treated dropwise with bromine $(0.004 \mathrm{~mol})$ in $10 \mathrm{~cm}^{3}$ of chloroform. The mixture was stirred for $10 \mathrm{~h}$ at room temperature. The separated solid was filtered, dried and crystallized (Koelsch 1950). 

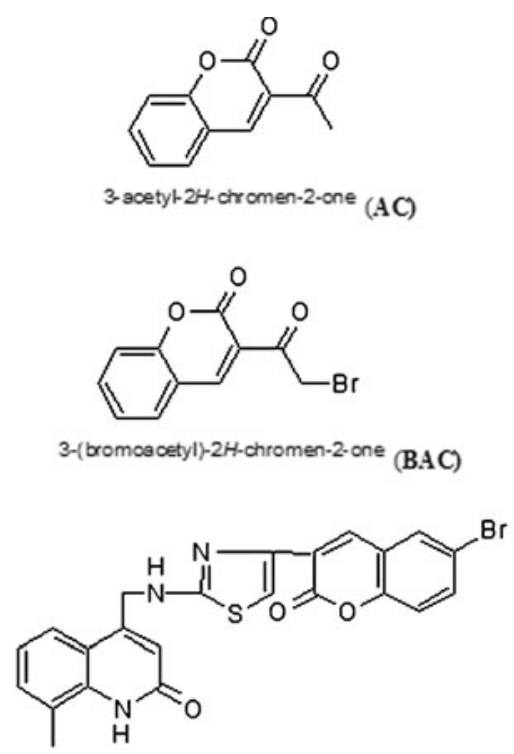

4-\{[4-(6-bromo-2-oxo-2H-chromen-3-yi)thia zol-2-ylamino]-methyl $\}-8-m e t h y 1-1 \mathrm{H}$ quinoline-2-one (BTMQ)<smiles>O=c1cc(CNc2nc(-c3cc4cc(Br)cc(Br)c4oc3=O)cs2)c2ccc(Cl)cc2[nH]1</smiles>

4-\{[4-(6,8-bromo-2-oxo-2H-chromen-3-y1)thiazol-2-ylamino]-methyl\}-7-chloro- $1 \mathrm{H}$ quinoline-2-one (BTCQ)

Figure 1. Chemical structures of inhibitors.

2.1c Triheterocyclic thiazoles: 4-amino methyl carbostyril hydrochloride $(0.003 \mathrm{~mol}-630 \mathrm{mg})$ in methanol $\left(20 \mathrm{~cm}^{3}\right)$ was taken in a $100 \mathrm{~cm}^{3} \mathrm{RB}$ flask and potassium thiocyanate $(0.006 \mathrm{~mol}-580 \mathrm{mg})$ was added to it. The reaction mixture was refluxed on a water bath for $3 \mathrm{~h}$. After cooling, separated solid of potassium chloride was filtered off. To the mother liquor, 3-bromo acetyl coumarin (0.003 mol-800 mg) was added and refluxing was continued for further $4 \mathrm{~h}$. The reaction mixture was left overnight. Yellow crystals of thiazole obtained were filtered and washed with more water.

\subsection{Weight loss studies}

Zinc sheets having rectangular shape with an exposed area of $2 \times 4 \times 1 \mathrm{~cm}$ were used for the corrosion rate measurements. The samples were first degreased with trichloroethylene, grounded with different grades of emery papers, washed with water and rinsed with alcohol. The dried and weighed samples were placed in $50 \mathrm{~cm}^{3}$ of $0.1 \mathrm{M} \mathrm{HCl}$ solutions with and without inhibitors for $2 \mathrm{~h}$ at $303 \mathrm{~K}$. Multiple experiments were performed in each case and the mean value of the weight loss was noted. Corrosion rate and inhibition efficiency (\% IE) were calculated.

\subsection{Potentiodynamic polarization studies}

The potentiodynamic polarization studies were carried out with zinc strips having an exposed area of $1 \mathrm{~cm}^{2}$. A conventional three electrode cell consisting of zinc as working electrode, platinum foil as counter electrode, and a saturated calomel electrode (SCE) as reference was used. Potentiodynamic polarization studies were carried out using an Autolab Potentiostat-Galvanostat and the data was analyzed using General purpose electrochemical system software. At a constant scan rate of $2 \mathrm{mV} \mathrm{s}^{-1}$ from open-circuit potential (OCP), anodic and cathodic polarization curves were obtained. The inhibition efficiencies were calculated from corrosion currents determined using the Tafel extrapolation method.

\subsection{Electrochemical impedance studies}

Electrochemical impedance measurements were carried out using an electrochemical system frequency response analyser (FRA). The electrochemical impedance spectra (EIS) were acquired in the frequency range $10 \mathrm{kHz}$ to $10 \mathrm{mHz}$ at the rest potential by applying $5 \mathrm{mV}$ sine wave $\mathrm{AC}$ voltage. The double layer capacitance (CPE) and the charge transfer resistance $\left(R_{\mathrm{p}}\right)$ were determined from Nyquist plots (Raghavan 2000). The inhibition efficiencies were calculated from $R_{\mathrm{p}}$ values.

\section{Results and discussion}

\subsection{Weight loss measurements}

Corrosion parameters obtained from weight loss measurements for various inhibitors on the corrosion rate of zinc metal in $0 \cdot 1 \mathrm{M} \mathrm{HCl}$ are recorded in table 1 . Figures 2 and 3 show the variation of dissolution rates and percentage inhibition (\% IE) efficiencies for BAC and BTCQ as representative compounds. It was observed that a significant decrease in dissolution rate occurred over the concentration range from $0.63 \times 10^{-4} \mathrm{M}$ to $5 \times 10^{-4} \mathrm{M}$ and corresponding increase in \%IE in case of AC, BAC, BTMQ and BTCQ. The highest $\%$ IE of $97 \%$ was observed with BAC having the concentration of $5 \times 10^{-4} \mathrm{M}$. The concentration of inhibitor at $5 \times 10^{-4} \mathrm{M}$ is taken as optimum concentration in our studies because above this concentration almost same \%IE was observed.

\subsection{Polarization studies}

The anodic dissolution of zinc and the cathodic evolution of hydrogen were carried out potentiodynamically in 
Table 1. Corrosion parameters obtained from weight loss, polarization and impedence measurements for zinc in $0 \cdot 1 \mathrm{M} \mathrm{HCl}$ containing various concentrations of inhibitors at $303 \mathrm{~K}$.

\begin{tabular}{|c|c|c|c|c|c|c|c|c|c|c|c|c|}
\hline \multirow{3}{*}{$\begin{array}{l}\text { Inhibitor } \\
\text { Blank }\end{array}$} & \multirow{2}{*}{$\begin{array}{l}\text { Concentration } \\
(\mathrm{M}) \times 10^{-4}\end{array}$} & \multirow{2}{*}{$\begin{array}{c}\begin{array}{c}\text { Corrosion rate } \\
\left(\mathrm{mg} \mathrm{cm}^{-2} \mathrm{hr}^{-1}\right)\end{array} \\
\text { Weight loss }\end{array}$} & \multirow{2}{*}{$\begin{array}{r}-E_{\text {corr }} \\
(\mathrm{mV})\end{array}$} & $\begin{array}{c}I_{\text {corr }} \\
\left(\mathrm{mA} \mathrm{cm}^{-2}\right)\end{array}$ & $\begin{array}{c}b_{\mathrm{a}} \\
(\mathrm{V} / \mathrm{dec})\end{array}$ & $\begin{array}{c}b_{\mathrm{c}} \\
(\mathrm{V} / \mathrm{dec})\end{array}$ & $\begin{array}{c}R_{\mathrm{S}} \\
(\mathrm{ohm})\end{array}$ & $\begin{array}{c}R_{\mathrm{p}} \\
(\mathrm{ohm})\end{array}$ & $\begin{array}{c}\mathrm{CPE} \\
\left(\mathrm{F} \mathrm{cm}^{2}\right) \times \\
10^{-3}\end{array}$ & \multirow{2}{*}{$\begin{array}{c}\% \text { IE } \\
\text { (Weight) }\end{array}$} & \multirow{2}{*}{$\begin{array}{c}\% \text { IE } \\
\text { (Tafel) }\end{array}$} & \multirow{2}{*}{$\begin{array}{l}\% \mathrm{IE} \\
\text { (Imp) }\end{array}$} \\
\hline & & & & \multicolumn{3}{|c|}{ Tafel polarizatiom } & \multicolumn{3}{|c|}{ Impedence } & & & \\
\hline & 0 & $1 \cdot 25$ & $1 \cdot 007$ & $0 \cdot 0215$ & $0 \cdot 276$ & $0 \cdot 245$ & 1.45 & 0.65 & $28 \cdot 6$ & - & - & - \\
\hline $\mathrm{AC}$ & $\begin{array}{l}0 \cdot 63 \\
1 \cdot 25 \\
2 \cdot 5 \\
5\end{array}$ & $\begin{array}{l}0.73 \\
0.53 \\
0.41 \\
0 \cdot 19\end{array}$ & $\begin{array}{l}1 \cdot 009 \\
0.998 \\
0.992 \\
0.974\end{array}$ & $\begin{array}{l}0.0133 \\
0 \cdot 0103 \\
0.0065 \\
0.0037\end{array}$ & $\begin{array}{l}0.271 \\
0.296 \\
0.278 \\
0.263\end{array}$ & $\begin{array}{l}0 \cdot 253 \\
0 \cdot 268 \\
0 \cdot 273 \\
0 \cdot 281\end{array}$ & $\begin{array}{l}1.98 \\
1.76 \\
1.93 \\
1.83\end{array}$ & $\begin{array}{l}1.08 \\
1.56 \\
2.73 \\
5.95\end{array}$ & $\begin{array}{c}17 \cdot 5 \\
13 \cdot 1 \\
7 \cdot 7 \\
5 \cdot 15\end{array}$ & $\begin{array}{l}42 \\
58 \\
72 \\
85\end{array}$ & $\begin{array}{l}38 \\
52 \\
70 \\
83\end{array}$ & $\begin{array}{l}39 \\
58 \\
76 \\
89\end{array}$ \\
\hline BAC & $\begin{array}{l}0 \cdot 63 \\
1.25 \\
2 \cdot 5 \\
5\end{array}$ & $\begin{array}{l}0 \cdot 54 \\
0 \cdot 3 \\
1 \cdot 3 \\
0 \cdot 04\end{array}$ & $\begin{array}{l}1 \cdot 008 \\
1.005 \\
0.996 \\
0.998\end{array}$ & $\begin{array}{l}0.0097 \\
0 \cdot 0060 \\
0 \cdot 0028 \\
0.0013\end{array}$ & $\begin{array}{l}0.252 \\
0 \cdot 238 \\
0.221 \\
0.197\end{array}$ & $\begin{array}{l}0 \cdot 224 \\
0 \cdot 210 \\
0 \cdot 196 \\
0 \cdot 179\end{array}$ & $\begin{array}{c}1.8 \\
1 \cdot 89 \\
2 \cdot 01 \\
1 \cdot 86\end{array}$ & $\begin{array}{l}1 \cdot 29 \\
2 \cdot 18 \\
4 \cdot 09 \\
9 \cdot 34\end{array}$ & $\begin{array}{c}14.9 \\
8.42 \\
5.42 \\
3.05\end{array}$ & $\begin{array}{l}57 \\
76 \\
90 \\
97\end{array}$ & $\begin{array}{l}55 \\
72 \\
87 \\
94\end{array}$ & $\begin{array}{l}49 \\
71 \\
81 \\
89\end{array}$ \\
\hline BTMQ & $\begin{array}{l}0.63 \\
1.25 \\
2.5 \\
5\end{array}$ & $\begin{array}{l}0 \cdot 7 \\
0 \cdot 49 \\
0 \cdot 26 \\
0 \cdot 1\end{array}$ & $\begin{array}{l}0.997 \\
0.985 \\
1.006 \\
1.018\end{array}$ & $\begin{array}{l}0.0123 \\
0.0093 \\
0.0050 \\
0.0026\end{array}$ & $\begin{array}{l}0.273 \\
0.330 \\
0 \cdot 375 \\
0.333\end{array}$ & $\begin{array}{l}0 \cdot 242 \\
0 \cdot 260 \\
0 \cdot 295 \\
0 \cdot 293\end{array}$ & $\begin{array}{l}1.64 \\
1.54 \\
1.67 \\
1.59\end{array}$ & $\begin{array}{l}1 \cdot 15 \\
1.87 \\
3.27 \\
4.67\end{array}$ & $\begin{array}{r}16 \cdot 5 \\
10 \cdot 9 \\
6 \cdot 6 \\
4 \cdot 3\end{array}$ & $\begin{array}{l}44 \\
61 \\
79 \\
92\end{array}$ & $\begin{array}{l}43 \\
57 \\
77 \\
88\end{array}$ & $\begin{array}{l}43 \\
65 \\
80 \\
86\end{array}$ \\
\hline BTCQ & $\begin{array}{l}0.63 \\
1.25 \\
2.5 \\
5\end{array}$ & $\begin{array}{l}0 \cdot 64 \\
0 \cdot 34 \\
0 \cdot 19 \\
0 \cdot 11\end{array}$ & $\begin{array}{l}0.974 \\
0.992 \\
1.008 \\
1.012\end{array}$ & $\begin{array}{l}0.0114 \\
0.0069 \\
0.0032 \\
0.0022\end{array}$ & $\begin{array}{l}0 \cdot 278 \\
0 \cdot 324 \\
0 \cdot 275 \\
0 \cdot 318\end{array}$ & $\begin{array}{l}0 \cdot 258 \\
0 \cdot 248 \\
0 \cdot 293 \\
0 \cdot 270\end{array}$ & $\begin{array}{l}1.57 \\
1.72 \\
1.91 \\
1.88\end{array}$ & $\begin{array}{l}1.07 \\
1.45 \\
2.26 \\
3.63\end{array}$ & $\begin{array}{c}17 \cdot 1 \\
13 \cdot 2 \\
7 \cdot 63 \\
4 \cdot 87\end{array}$ & $\begin{array}{l}49 \\
73 \\
85 \\
91\end{array}$ & $\begin{array}{l}47 \\
68 \\
82 \\
90\end{array}$ & $\begin{array}{l}39 \\
55 \\
71 \\
82\end{array}$ \\
\hline
\end{tabular}

acidic chloride solution containing various concentrations of inhibitors. Figures 4 and 5 show the effects of BAC and BTCQ on the cathodic and anodic polarization of zinc in acidic chloride solution. Similar curves were obtained for AC and BTMQ. The presence of the inhibitors in the solution shifted the anodic polarization curves to more positive values and cathodic polarization curves to more negative potentials. The corrosion current densities were determined by extrapolating the anodic and cathodic Tafel lines to the free corrosion potentials.

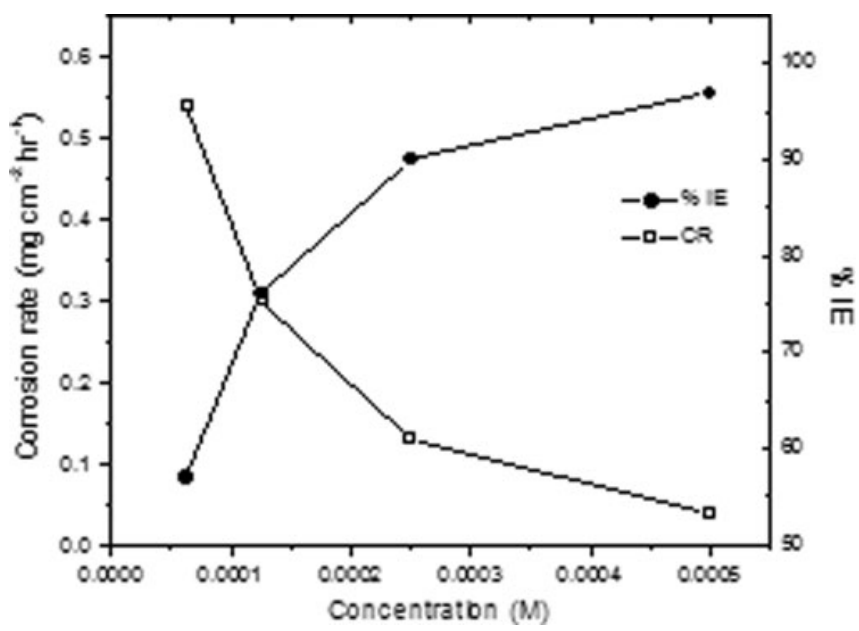

Figure 2. Variation of $\mathrm{CR}$ and \% IE with concentration of BAC obtained from weight loss method.
Electrochemical corrosion parameters like corrosion potential, corrosion current density, cathodic and anodic Tafel slopes values and inhibition efficiencies (\%IE) are given in table 1. Addition of inhibitors reduced the corrosion current of zinc in acid chloride solution. Thus the results in the table 1 indicated that the inhibition efficiency increased with the inhibitor concentration.

The anodic and cathodic Tafel slopes in the presence of AC, BAC, BTMQ and BTCQ indicated that the inhibitors interfered with the cathodic and anodic reactions. Table 1

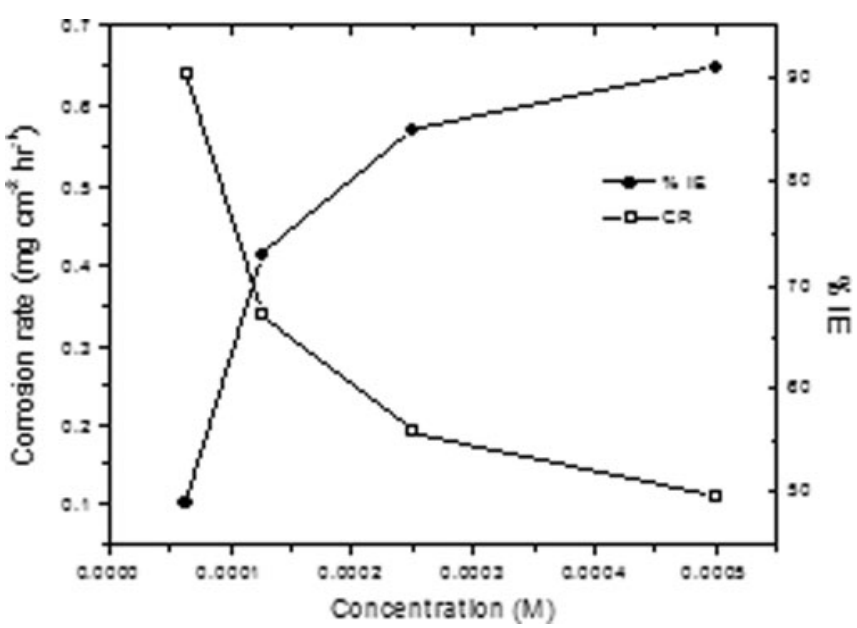

Figure 3. Variation of CR and \% IE with concentration of BTCQ obtained from weight loss method. 


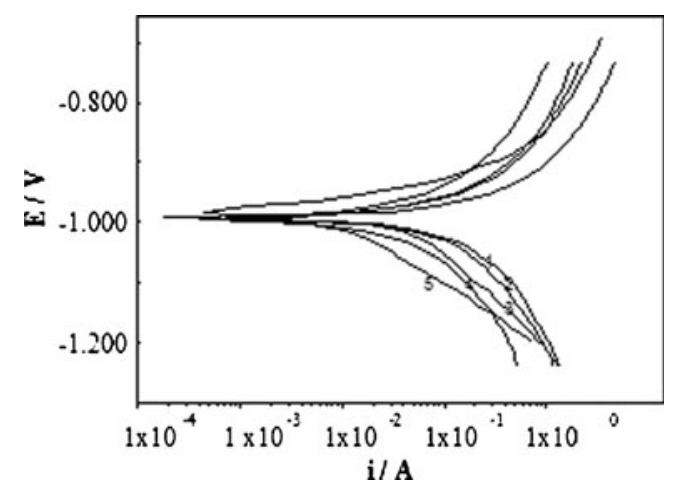

Figure 4. Polarization curves of zinc in $0 \cdot 1 \mathrm{M} \mathrm{HCl}$ in the presence of different concentrations of BAC at $303 \mathrm{~K}$. (1) HCl blank, (2) $0.63 \times 10^{-4} \mathrm{M}$, (3) $1.25 \times 10^{-4} \mathrm{M}$, (4) $2.5 \times 10^{-4} \mathrm{M}$, (5) $5 \times 10^{-4} \mathrm{M}$.

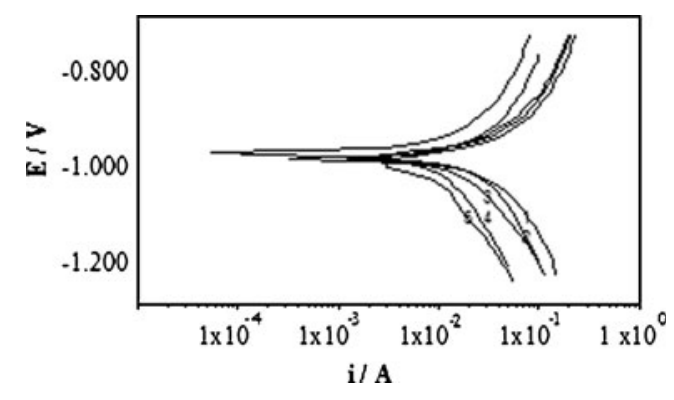

Figure 5. Polarization curves of zinc in $0 \cdot 1 \mathrm{M} \mathrm{HCl}$ in the presence of different concentrations of BTCQ at $303 \mathrm{~K}$. (1) $\mathrm{HCl}$ blank, (2) $0.63 \times 10^{-4} \mathrm{M}$, (3) $1.25 \times 10^{-4} \mathrm{M}$, (4) $2.5 \times 10^{-4} \mathrm{M}$, (5) $5 \times 10^{-4} \mathrm{M}$.

shows that the values of the anodic $\left(b_{a}\right)$ and cathodic $\left(b_{c}\right)$ Tafel slopes obtained in the absence and presence of inhibitors are approximately the same. This indicated the mixed type of control by the inhibitors (Rudresh and Mayanna 1977).

\subsection{Electrochemical impedance spectroscopy (EIS)}

Impedance measurements of zinc immersed in $0 \cdot 1 \mathrm{M} \mathrm{HCl}$ solutions without and with BAC and BTCQ are presented in the form of Nyquist plots in figures 6 and 7, respectively. Equivalent circuit is shown in figure 8. Inhibitors AC and BTMQ also gave plots of similar nature.

It was observed that as the concentration of inhibitor increased, the diameter of capacitive loop and consequently the values of charge transfer resistance $\left(R_{\mathrm{p}}\right)$ increased, which was an indication of the inhibiting action. Values of EIS parameters corresponding to the impedance spectra recorded in the presence of the investigated compounds are listed in table 1 .

The value of the electrolyte resistance $\left(R_{\mathrm{S}}\right)$ obtained in the pure medium increased in the presence of the investigated

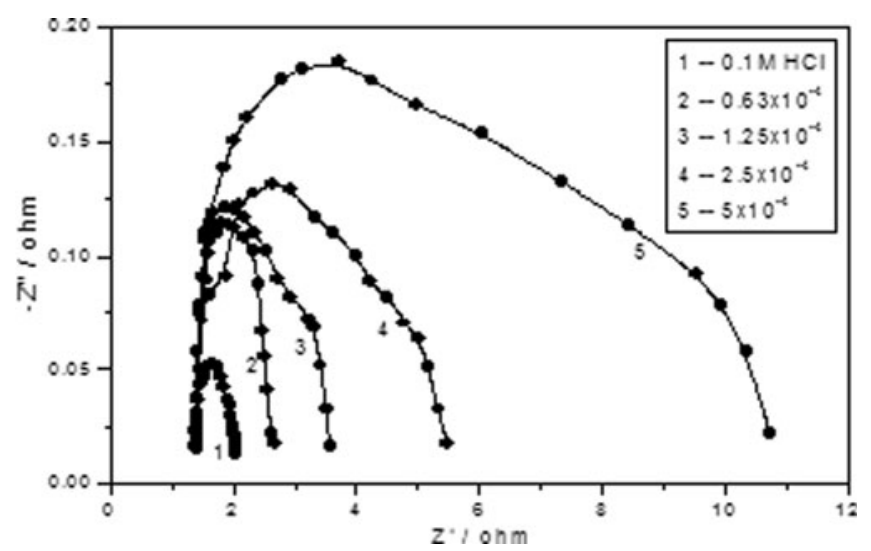

Figure 6. Nyquist plots for zinc in $0.1 \mathrm{M} \mathrm{HCl}$ in the absence and presence of different concentrations of BAC.

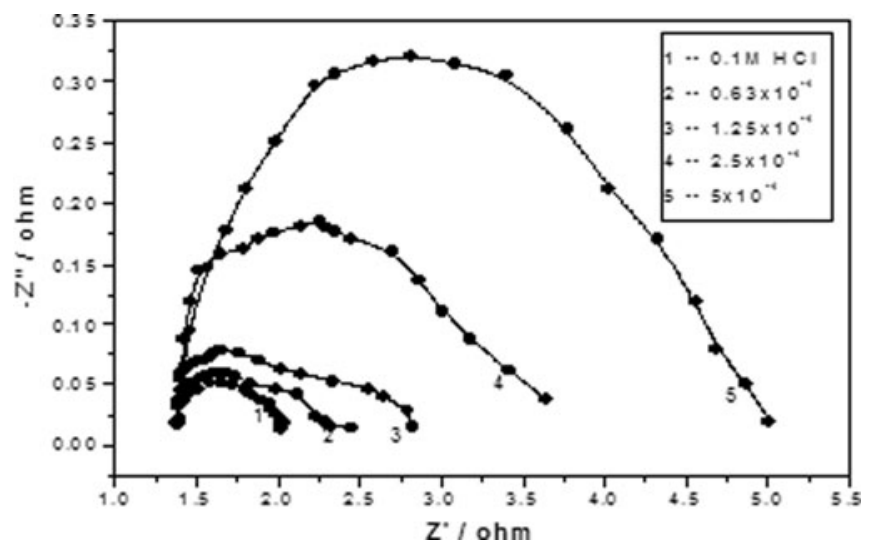

Figure 7. Nyquist plots for zinc in $0 \cdot 1 \mathrm{M} \mathrm{HCl}$ in the absence and presence of different concentrations of BTCQ.

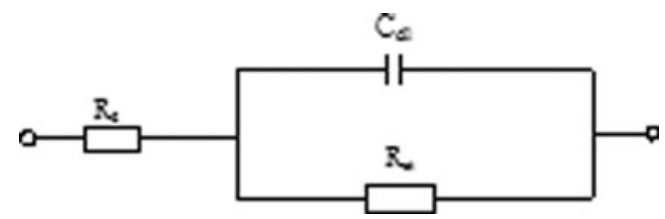

Figure 8. Equivalent circuit for the electrochemical impedance measurements.

compounds. This was attributed to the change in the conductivity of the medium. Besides the increase in value of $R_{\mathrm{p}}$, the value of CPE obtained in the blank solution is drastically decreased in the presence of inhibitor. This was correlated to the decrease in the area on zinc surface exposed to corrosive solution (increase in the area covered with the inhibitor) as 

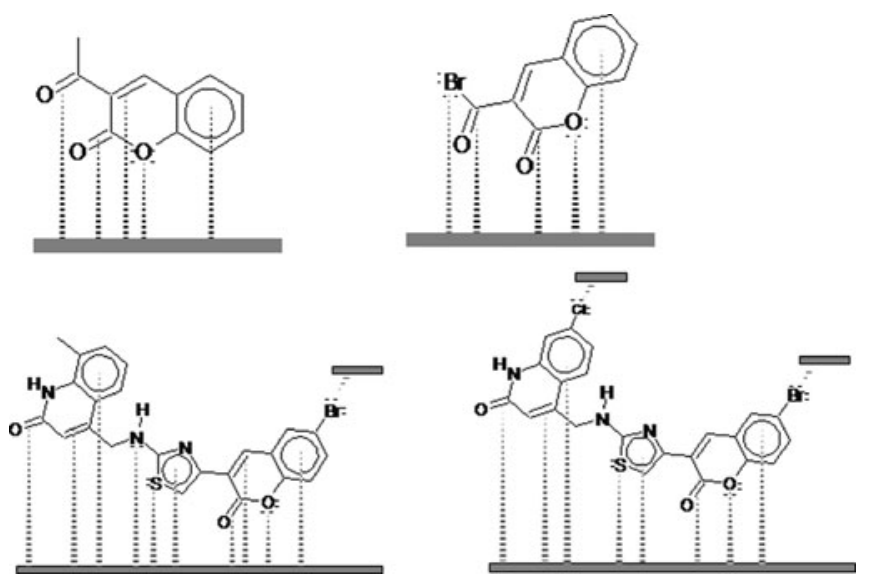

Figure 9. Skeletal representation of the lone pair and $\pi$ electron interactions of the inhibitor molecules with steel surface.

a result of adsorption. Hence the corrosion rate was appreciably decreased in the presence of the inhibitors. Figure 9 shows the possible skeletal interaction of the lone pair and $\pi$ electron of the inhibitor molecules with zinc surface.

\subsection{Adsorption isotherms}

The nature of inhibitor interaction with the corroding surface during corrosion inhibition of metal was deduced in terms of adsorption characteristics of the inhibitors. The surface coverage $(\theta)$ data was generally employed to explain adsorption characteristics. Although the weight loss and cur- rent density measurements are correlated to surface coverage, they did not represent the same magnitude of corrosion rate (table 2). The $\theta$ values generated from direct measurement of weight loss were greater than polarization measurements. This was probably because of slight etching of the surface during corrosion.

The values of $\theta$ and $C$ (concentration of the inhibitor solution) were tested by fitting to the various isotherms. Attempts were made to fit the values of $\theta$ and $C$ of the studied inhibitor from mass loss experiments with several adsorption isotherms like Langmuir, Temkin, Freundlich and FloryHuggins. However, the best fit was obtained with Langmuir isotherm plots of $\log \theta / 1-\theta$ versus $\log C$ gave straight lines with a slope of nearly unity for the investigated compounds (figure 10), indicating that the adsorption of inhibitors on zinc obeyed Langmuir adsorption isotherm.

\subsection{Thermodynamic parameters}

The surface coverage $(\theta)$ was calculated using the equation $1-\theta=i^{*} / i$, where $i^{*}$ and $i$ are the corrosion currents with and without inhibitors. The apparent free energy of adsorption $\left(\Delta G^{0}\right)$ was calculated from the relation

$$
\Delta G^{0}=-2.303 \mathrm{RT} \log 55.5 \mathrm{~K}, \text { where } K=\theta / C(1-\theta) .
$$

Values of surface coverage $(\theta)$, equilibrium constant $(K)$ and free energy of adsorption $\left(\Delta G^{0}\right)$ at different concentrations of AC, BAC, BTMQ and BTCQ are given in table 2. The negative values of $\Delta G^{0}$ indicated the spontaneous adsorption of the inhibitor and revealed strong interaction between inhibitor molecules and metal surface. The values of

Table 2. Adsorption parameters for the inhibitors tested on zinc in $0 \cdot 1 \mathrm{M} \mathrm{HCl}$ solution at $303 \mathrm{~K}$.

\begin{tabular}{|c|c|c|c|c|c|}
\hline \multirow[b]{2}{*}{ Inhibitor } & \multirow{2}{*}{$\begin{array}{l}\text { Concentration } \\
(\mathrm{M}) \times 10^{-4}\end{array}$} & \multicolumn{2}{|c|}{$\theta$} & \multirow[b]{2}{*}{$10^{-3} \times \mathrm{K}$} & \multirow[b]{2}{*}{$-\Delta G$} \\
\hline & & Weight loss & Polarization & & \\
\hline \multirow[t]{4}{*}{$\mathrm{AC}$} & 0.63 & 0.42 & $0 \cdot 38$ & $9 \cdot 8$ & $33 \cdot 28$ \\
\hline & $1 \cdot 25$ & 0.58 & 0.52 & 8.67 & 32.97 \\
\hline & $2 \cdot 5$ & 0.72 & 0.70 & $9 \cdot 33$ & $33 \cdot 15$ \\
\hline & 5 & 0.85 & 0.83 & 9.76 & $33 \cdot 24$ \\
\hline \multirow[t]{4}{*}{ BAC } & 0.63 & 0.57 & 0.55 & $19 \cdot 56$ & $35 \cdot 02$ \\
\hline & 1.25 & 0.76 & 0.72 & $20 \cdot 57$ & $35 \cdot 14$ \\
\hline & $2 \cdot 5$ & 0.90 & $0 \cdot 87$ & $26 \cdot 77$ & $35 \cdot 81$ \\
\hline & 5 & 0.97 & 0.94 & $31 \cdot 33$ & $36 \cdot 2$ \\
\hline \multirow[t]{4}{*}{ BTMQ } & 0.63 & 0.44 & 0.43 & $12 \cdot 07$ & $33 \cdot 8$ \\
\hline & 1.25 & 0.61 & 0.57 & $10 \cdot 6$ & 33.47 \\
\hline & $2 \cdot 5$ & 0.79 & 0.77 & $13 \cdot 39$ & 34.06 \\
\hline & 5 & 0.92 & 0.88 & $14 \cdot 67$ & $34 \cdot 29$ \\
\hline \multirow[t]{4}{*}{ BTCQ } & 0.63 & 0.49 & 0.47 & $14 \cdot 19$ & $34 \cdot 2$ \\
\hline & 1.25 & 0.73 & 0.68 & $17 \cdot 0$ & 34.66 \\
\hline & $2 \cdot 5$ & 0.85 & $0 \cdot 82$ & $17 \cdot 78$ & 34.78 \\
\hline & 5 & 0.91 & 0.90 & $18 \cdot 0$ & $34 \cdot 81$ \\
\hline
\end{tabular}




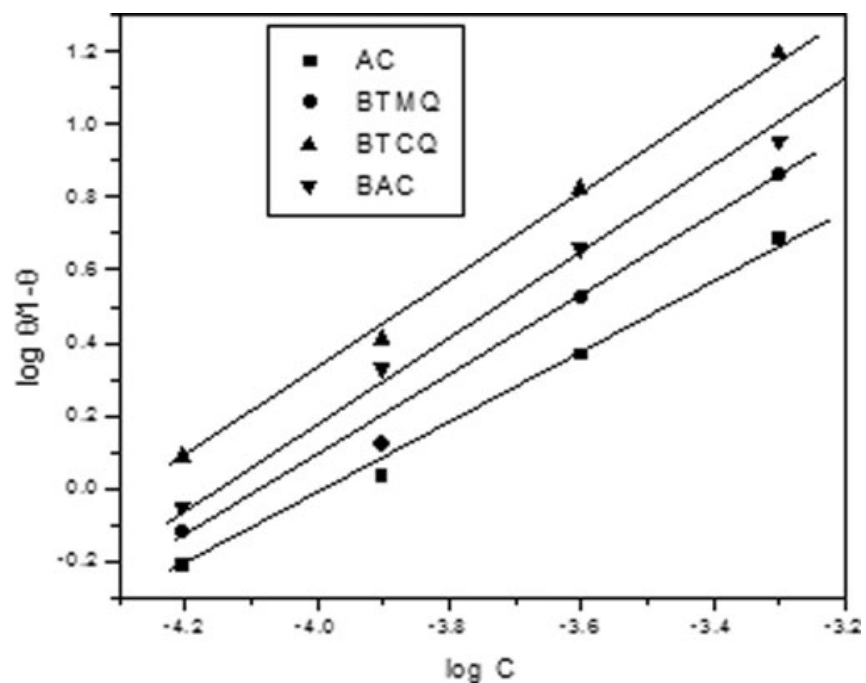

Figure 10. Langmuir adsorption isotherm for zinc in $0.1 \mathrm{M} \mathrm{HCl}$ containing various concentrations of inhibitor from polarization study.

equilibrium constant for $\mathrm{BAC}$ is highest and that of $\mathrm{AC}$ being lowest, AC provided the poorest protection and BAC the highest against zinc corrosion. This is also supported by higher negative $\Delta G^{0}$ values for BAC.

\section{Conclusions}

Addition of AC, BAC, BTMQ and BTCQ inhibited the corrosion of zinc in $\mathrm{HCl}$ solution. The \% IE was maximum for $\mathrm{BAC}$ and was in the order $\mathrm{BAC}>\mathrm{BTMQ}>\mathrm{BTCQ}>\mathrm{AC}$. Inhibition efficiency increased with inhibitor concentra- tion. The investigated compounds inhibited both anodic and cathodic reaction by adsorption. The adsorption of molecules was found to obey Langmuir adsorption isotherm. The \% IE obtained from weight loss, polarization and impedance methods were in good agreement.

\section{References}

Aramaki K 2002 Corros. Sci. 441375

Arenas M A and Damborenea J J 2004 Surf. Coat. Technol. 187320

Bellezze T, Roventi G and Fratesi R 2002 Surf. Coat. Technol. 155221

Bentiss F, Lagrenee M, Traisnel M and Hornez J C 1999 Corrosion 968

Bouyanzer A, Hammouti B, Majidi L and Haloui B 2010 Port. Electrochim. Acta 28165

Buu-Hoi N P, Loc T B and Xuong N D 1957 Bull. Soc. Chem. France 561 Chem. Abstr. 5112895

El-Mahdy G A and Mohmoud S S 1995 Bull. Electrochem. 11222

Ferreira M G S, Duarte R G, Montemor M F and Simoes A M P 2004 Electrochim. Acta 492927

Gad Allah A G, Hefny M M, Salih S A and El-Basiouny M S 1998 Corrosion 574

Knoevengel E 1898 Ber. 31730

Koelsch C F 1950 J. Am. Chem. Soc. 722993

Raghavan P V 2000 Expert consultant (CPCSEA, OECD, guideline No. 420)

Raja P B and Sethuraman M G 2008 Mater. Lett. 62113

Rodney L and Leroy 1978 Corrosion NACE 98

Rudresh H B and Mayanna S M 1977 Br. Corros. J. 12

Stupnisek-Lisac E and Metikos-Hukovia M 1993 Br. Corros. J. 2874

Swiatowska-Mrowiecka J, Zanna S, Ogle K and Marcus P H 2008 Appl. Surf. Sci. 2545530

Tamil Selvi S, Raman V and Rajendran N 2003 J. Appl. Electrochem. $\mathbf{3 3} 1175$ 